\title{
Change of Ginsenoside Profiles in Processed Ginseng by Drying, Steaming, and Puffing
}

\author{
Ji-Hye Shin ${ }^{1}$, Young Joon Park ${ }^{2}$, Wooki Kim ${ }^{1}$, Dae-Ok Kim ${ }^{1}$, Byung-Yong Kim${ }^{1}$, Hyungjae Lee ${ }^{3 *}$, and \\ Moo-Yeol Baik ${ }^{1 *}$ \\ ${ }^{1}$ Department of Food Science and Biotechnology, Institute of Life Science and Resources, Kyung Hee University, Yongin 17104, Republic of Korea \\ ${ }^{2}$ Department of Science in Korean Medicine, Graduate School, Kyung Hee University, Seoul 02447, Republic of Korea \\ ${ }^{3}$ Department of Food Engineering, Dankook University, Cheonan 31116, Republic of Korea
}

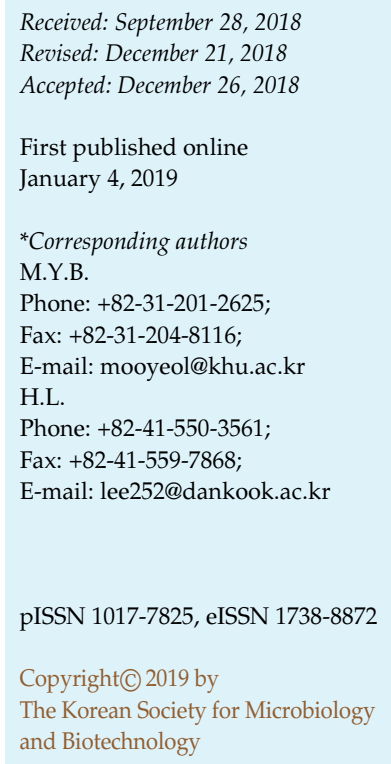

Korean ginseng (Panax ginseng Meyer) was processed by drying, steaming, or puffing, and the effects of these processes on the ginsenoside profile were investigated. The main root of 4-year-old raw Korean ginseng was dried to produce white ginseng. Steaming, followed by drying, was employed to produce red or black ginseng. In addition, these three varieties of processed ginseng were puffed using a rotational puffing gun. Puffed ginseng showed significantly higher extraction yields of ginsenosides (49.87-58.60 g solid extract/100 g of sample) and crude saponin content (59.40-63.87 mg saponin/g of dried ginseng) than nonpuffed ginseng, respectively. Moreover, puffing effectively transformed the major ginsenosides (Rb1, Rb2, Rc, Rd, Re, and Rg1) of ginseng into minor ones (F2, Rg3, Rk1, and Rg5), comparable to the steaming process effect on the levels of the transformed ginsenosides. However, steaming takes much longer (4 to 36 days) than puffing (less than $30 \mathrm{~min}$ ) for ginsenoside transformation. Consequently, puffing may be an effective and economical technique for enhancing the extraction yield and levels of minor ginsenosides responsible for the major biological activities of ginseng.

Keywords: Ginsenoside profile, Panax ginseng Meyer, drying, steaming, puffing

\section{Introduction}

The root of ginseng, Panax ginseng Meyer (Araliaceae), has frequently been used as a traditional medicine in Asian countries. Ginseng products are increasingly popular and are readily available in pharmacies and health food stores worldwide. Functional ingredients in ginseng include saponins, phenolic compounds, polyacetylenes, alkaloids, and polysaccharides [1]. Among the saponins in ginseng, ginsenosides are the main effective components responsible for the antidiabetic [2,3], antiallergic [4], and antitumor [5] activities of ginseng. More than forty ginsenosides have been identified and characterized [6] based on their aglycone moieties [7], which can be categorized into three types: protopanaxadiol (PPD), protopanaxatriol (PPT), and oleanolic acid. It has been reported that minor ginsenosides such as Rg3, Rk1, Rg5, and F2 possess higher functionality and bioavailability, compared with major ginsenosides such as $\mathrm{Rb} 1, \mathrm{Rb} 2, \mathrm{Rc}, \mathrm{Rd}, \mathrm{Re}$, and $\mathrm{Rg} 1$ [8]. Ginsenoside $\mathrm{Rg} 3$ was reported to potentiate a variety of pharmacological outcomes including protection against tumors [9], hepatoprotection [10], immunomodulation [11], and neuroprotection [12]. The degradation products of ginsenosides $\mathrm{Rk} 1$ and $\operatorname{Rg} 5$, caused by high temperature and pressure, also have pharmaceutical value [13]. Ginsenoside F2 is produced through the decomposition of glucose at the $C-3$ residue of ginsenoside Rd [14]. To preserve ginseng for an extended period of time, the fresh root is traditionally dried to produce white ginseng or steamed and dried to produce red or black ginseng. These processing procedures transform major ginsenosides including $\mathrm{Rb} 1, \mathrm{Rb} 2, \mathrm{Rc}, \mathrm{Rd}, \mathrm{Re}$, and $\operatorname{Rg} 1$ into minor ginsenosides including $\operatorname{Rg} 3, \mathrm{Rk} 1, \operatorname{Rg} 5$, and 
F2. The characteristic compounds in red and black ginseng have potential biological activities including anticancer, antidiabetic, neuroprotective, and anti-inflammatory activities [15-19].

The puffing process, which uses a rotating cylinder under a high temperature flame and causes a sudden release of water vapor pressure, leads to explosive puffing of cereals such as corn, rice, and soybeans [20]. The puffing process employs heat and pressure to modify the physicochemical properties of foods for the improvement of practical properties [21]; the process weakens the binding forces in plant tissues through heat treatment, and consequently facilitates the solubilization of the functional components. Furthermore, the original structure is broken down during the puffing process due to an increase in the specific volume of moisture or gas in the puffed samples [20]. Among food processing procedures, high-temperature and short-time puffing, as well as chemical processes such as starch gelatinization, denaturation and texturization of proteins, enzyme inactivation, changes in ingredients, and deodorization can cause various physical and chemical changes in foods and herbal medicines [22]. It has been reported that puffed raw ginseng and puffed red ginseng have higher extraction yields and crude saponin content than both non-puffed raw and red ginseng [23], and also contain increased amounts of ginsenosides $\operatorname{Rg} 3, \operatorname{Rg} 5$, and Rk1 [21]. However, there have been few studies on changes in the ginsenoside composition of puffed white and black ginseng.

In this study, we aimed to investigate the effects of the drying, steaming and puffing processes on the extraction yield and crude saponin content of ginseng. Moreover, ginsenoside profiles for white, red, and black ginseng and their puffed versions were analyzed to elucidate changes in their respective ginsenosides under these different processing procedures.

\section{Materials and Methods}

\section{Materials}

Four-year-old raw Korean ginseng roots were purchased from Hankook Ginseng Co. (Korea). The ginsenoside standards, Rb1, $\mathrm{Rb} 2$, Rc, Rd, Re, Rg1, Rg3, F2, Rg5, and Rk1, were purchased from BTGin Co., Ltd. (Korea). HPLC grade acetonitrile and methanol were obtained from Fisher Scientific (USA) and ethanol of analytical grade was purchased from Daehan Ethanol Life Co. (Korea). Water was purified using a Milli-Q system (Millipore, USA). All the solutions were filtered through a $0.45 \mu \mathrm{m}$ hydrophilic polypropylene membrane prior to use.
Steaming and Drying Processes: White, Red, and Black Ginseng

Ginseng main roots were washed with tap water to remove soil and other debris. White ginseng was prepared from raw ginseng through forced-convection drying at $55^{\circ} \mathrm{C}$ for 7 days until the final moisture content was less than $14 \%$ [24]. Red ginseng was manufactured by steaming raw ginseng root at $97^{\circ} \mathrm{C}$ for $3 \mathrm{~h}$ using an autoclave (HK-AC60, Hankuk S\&I Co., Korea). After cooling to room temperature, the autoclaved ginseng was dried at $70^{\circ} \mathrm{C}$ for $24 \mathrm{~h}$, and then at $50^{\circ} \mathrm{C}$ for $72 \mathrm{~h}$ in a forced-convection drying oven. Black ginseng was made using nine cycles of two consecutive processes: steaming raw ginseng root at $97^{\circ} \mathrm{C}$ for $3 \mathrm{~h}$, followed by a three-step drying process at each cycle in a forced-convection drying oven at $60^{\circ} \mathrm{C}$. The first drying was for $36 \mathrm{~h}$, the second drying for $14 \mathrm{~h}$, and the remaining seven drying cycles for $12 \mathrm{~h}$ [25].

\section{Puffing}

Dried white, red, and black ginseng samples were puffed with rice (ginseng:rice $=1: 4, \mathrm{w} / \mathrm{w}$ ) to avoid burning [21,23]. The mixture $(\sim 1 \mathrm{~kg})$ was heated in the chamber of a traditional rotary puffing machine. When the gauge pressure of the chamber reached $490 \mathrm{kPa}$, the valve was opened to reduce the pressure to $196 \mathrm{kPa}$. The chamber was reheated to reach the desired pressure of $784 \mathrm{kPa}$. At the indicated pressure, the lid was quickly removed. The resulting puffed ginseng samples were separated from the puffed rice and subsequently cooled to room temperature, sealed, and stored in a refrigerator [21].

\section{Non-Thermal Extraction of Raw Ginseng}

A 200-g sample of raw ginseng was ground with $4 \mathrm{~L}$ of $70 \%(\mathrm{v} / \mathrm{v})$ ethanol, and then centrifuged at $8,870 \mathrm{~g}$ for $1 \mathrm{~h}$. The supernatant was prepared as a non-thermal extract of raw ginseng. The extract was filtered through Whatman No. 2 filter paper (Whatman; UK). One $\mathrm{ml}$ of the extract was transferred to a tared aluminum dish, dried at $105^{\circ} \mathrm{C}$ to a constant weight, and then cooled in a desiccator. Extraction yield was expressed as g solid extract/100 g of sample.

\section{Thermal Extraction of Raw, White, Red, and Black Ginseng}

A heat reflux method was used for thermal extraction of puffed or non-puffed raw, white, red, and black ginseng. Approximately $200 \mathrm{~g}$ of ginseng was mixed with $4 \mathrm{~L}$ of $70 \%(\mathrm{v} / \mathrm{v})$ ethanol and extracted in a reflux machine (HASCOM Red Ginseng Extractor; Jungsung HASCOM, Korea) at $70^{\circ} \mathrm{C}$ for $24 \mathrm{~h}$ [23]. After extraction, the ginseng extract was cooled, and $1 \mathrm{ml}$ of extract was transferred to a tared aluminum dish, dried at $105^{\circ} \mathrm{C}$ to a constant weight, and then cooled in a desiccator. Extraction yield was calculated as $\mathrm{g}$ solid extract/100 $\mathrm{g}$ of sample.

\section{Crude Saponin Content}

Crude saponin content was analyzed according to the method described by Ando et al. [26]. The evaporated residue (4 g) was 
dissolved in $120 \mathrm{ml}$ distilled water and washed three times with $120 \mathrm{ml}$ diethyl ether in a separatory funnel to remove lipids in the extract. The aqueous layer was extracted three times with $120 \mathrm{ml}$ water-saturated $n$-butanol. The resulting butanol layer was washed three times with $120 \mathrm{ml}$ distilled water to remove impurities. The remaining butanolic solution was transferred to a tared roundbottom flask, where the $n$-butanol fraction was evaporated at $55^{\circ} \mathrm{C}$ using a rotary vacuum evaporator (Rotavapor R-124, BÜCHI Labortechnik AG, Flawil, Switzerland). After evaporation, the flask was dried at $105^{\circ} \mathrm{C}$, cooled in a desiccator, and dried to a constant weight. Crude saponin content was expressed as $\mathrm{mg}$ crude saponin/g of dried ginseng.

\section{Ginsenoside Analysis}

An HPLC system, Futecs NS3000i (Korea) with a UV/VIS detector and a gradient pump, was used for ginsenoside analysis of the processed ginseng samples. The HPLC system was equipped with a Supelco Discovery C18 $(4.6 \mathrm{~mm} \times 250 \mathrm{~mm}, 5 \mu \mathrm{m})$ column (USA) at a flow rate of $1.6 \mathrm{ml} / \mathrm{min}$, and was monitored at $203 \mathrm{~nm}$. The binary gradient elution system consisting of water (solvent A) and acetonitrile (solvent B) was achieved using the following gradient conditions: 0-30 min, 0 to $20 \%$ B; 30-65 min, 20 to $45 \% \mathrm{~B} ; 65-75 \mathrm{~min}, 45$ to $90 \% \mathrm{~B} ; 75-85 \mathrm{~min}, 90 \% \mathrm{~B} ; 85-87 \mathrm{~min}, 90$ to $20 \% \mathrm{~B} ; 87-100 \mathrm{~min}, 20 \% \mathrm{~B}$. Quantitative analysis was performed as described by Sun et al. [27]. The linearity, regression, and linear ranges of ten ginsenosides were calculated. A correlation coefficient $\left(r^{2}\right)$ higher than 0.99 indicated that there were appropriate correlations between the concentrations of ginsenosides and their peak areas within the test ranges.

\section{Statistical Analysis}

Duplicate samples were used in each experiment, and each sample was analyzed at least three times. One-way analysis of variance (ANOVA) was performed to determine the difference among the average values. Statistical significance was tested using Duncan's multiple range tests. Statistical tests were performed using SAS version 9.0 (SAS Institute, Inc., USA) with a $95 \%$ confidence level.

\section{Results and Discussion}

\section{Non-Thermal and Thermal Extractions}

The extraction yields of non-thermally or thermally extracted raw ginseng were 43.28 and $36.22 \mathrm{~g}$ solid extract/ $100 \mathrm{~g}$ of sample, respectively (Table 1 ). The extraction yield of non-thermally extracted raw ginseng was significantly higher than that of thermally extracted raw ginseng. Nonthermally extracted raw ginseng was pulverized in $70 \%$ ethanol to destroy the cell walls in raw ginseng, resulting in easier transfer of soluble solids to solvent. In contrast, the crude saponin content of non-thermally extracted ginseng (16.44 mg/g dried ginseng) was much lower than that of thermally extracted ginseng $(33.95 \mathrm{mg} / \mathrm{g}$ dried ginseng) (Table 1). This result suggested that thermal extraction is more effective than non-thermal extraction to obtain a higher content of crude saponin.

Figs. $1 \mathrm{~A}$ and $1 \mathrm{~B}$ show the ginsenoside profiles of nonthermally and thermally extracted raw ginseng analyzed by HPLC, respectively. The ginsenoside profiles of the nonthermally and thermally extracted ginseng were similar, but the levels of Rb1, Rb2, Rc, and Rd in non-thermally extracted ginseng were significantly lower than those of thermally extracted ginseng (Table 2). This may be due to the demalonylation of malonyl ginsenosides during thermal extraction, as malonyl ginsenosides have been reported to be thermally unstable and may be demalonylated during thermal extraction [28]; the malonyl ginsenosides (m-Rb1, $\mathrm{m}-\mathrm{Rb} 2, \mathrm{~m}-\mathrm{Rc}$, and $\mathrm{m}-\mathrm{Rd}$ ) may have been transformed into the corresponding neutral ginsenosides ( $\mathrm{Rb} 1, \mathrm{Rb} 2, \mathrm{Rc}$, and $\mathrm{Rd}$ ) during thermal extraction, resulting in the higher ginsenoside content in thermally extracted ginseng.

\section{Effect of Steaming Process}

Table 1 summarizes the effect of the steaming process on the extraction yields and crude saponin content of ginseng

Table 1. Extraction yields and crude saponin contents of raw and processed ginseng by drying, steaming, and puffing.

\begin{tabular}{|c|c|c|c|c|}
\hline \multicolumn{2}{|c|}{ Processing } & \multirow{2}{*}{ Ginseng } & \multirow{2}{*}{$\begin{array}{c}\text { Extraction yield }^{1)} \\
\text { (g solid extract/100 } \mathrm{g} \text { of sample) }\end{array}$} & \multirow{2}{*}{$\begin{array}{l}\text { Crude saponin content }^{1)} \\
(\mathrm{mg} / \mathrm{g} \text { of dried ginseng) }\end{array}$} \\
\hline Heating & Puffing & & & \\
\hline Non-thermal & Non-puffed & Raw ginseng & $43.28 \pm 3.69^{c}$ & $16.44 \pm 1.77^{g}$ \\
\hline \multirow{6}{*}{ Thermal } & Non-puffed & Raw ginseng & $36.22 \pm 1.17^{d}$ & $33.95 \pm 1.73^{f}$ \\
\hline & & White ginseng & $35.37 \pm 0.33^{\mathrm{d}}$ & $35.55 \pm 0.60^{\mathrm{e}}$ \\
\hline & & Red ginseng & $40.47 \pm 0.47^{c}$ & $37.55 \pm 1.87^{\mathrm{d}}$ \\
\hline & Puffed & White ginseng & $50.80 \pm 0.80^{b}$ & $62.57 \pm 2.57^{b}$ \\
\hline & & Red ginseng & $49.87 \pm 0.31^{\mathrm{b}}$ & $59.40 \pm 0.53^{c}$ \\
\hline & & Black ginseng & $58.60 \pm 2.11^{\mathrm{a}}$ & $63.87 \pm 4.44^{\mathrm{a}}$ \\
\hline
\end{tabular}

\footnotetext{
${ }^{1)}$ Means with the same superscript in the same column are not significantly different by Duncan's multiple range test $(p<0.05)$.
} 


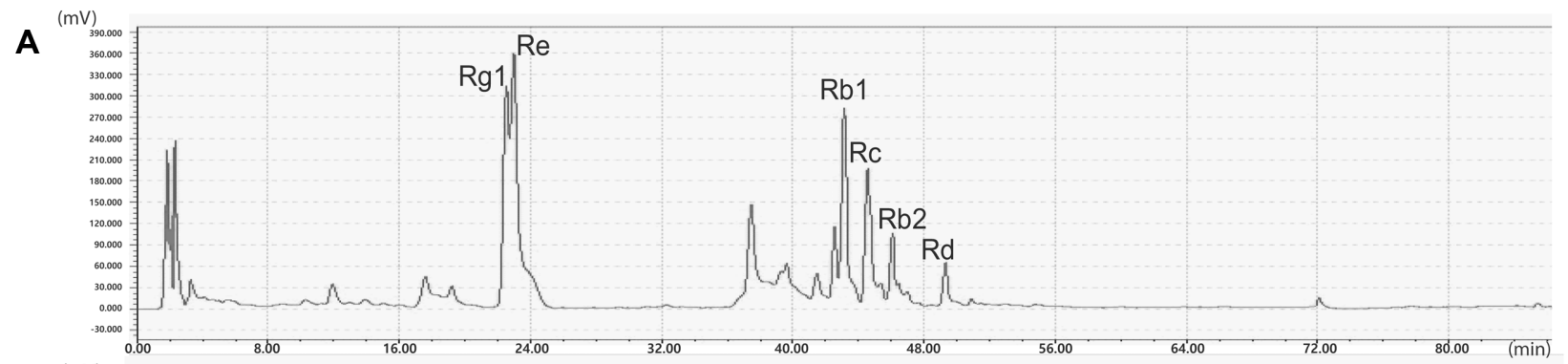

B
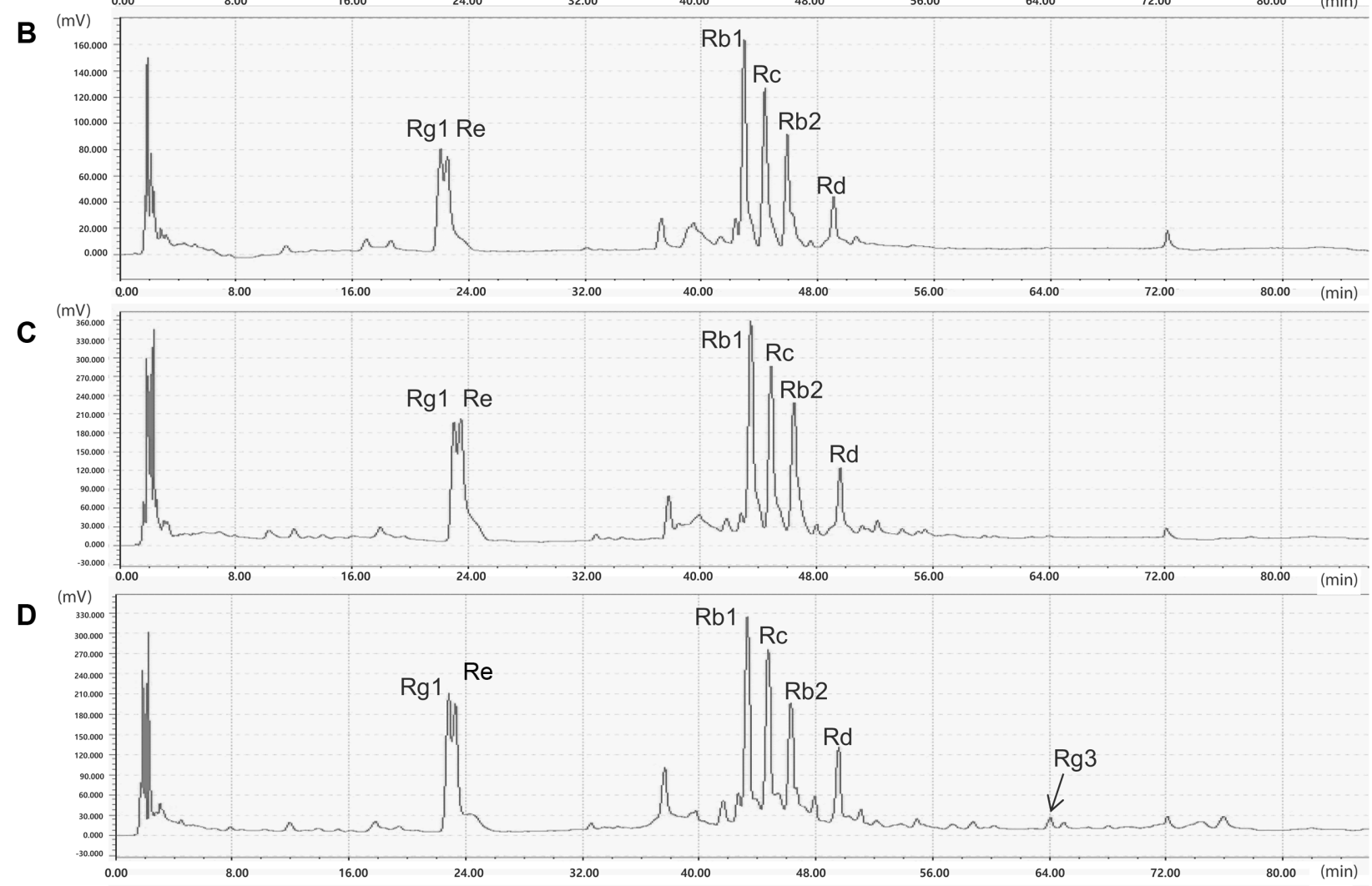

E

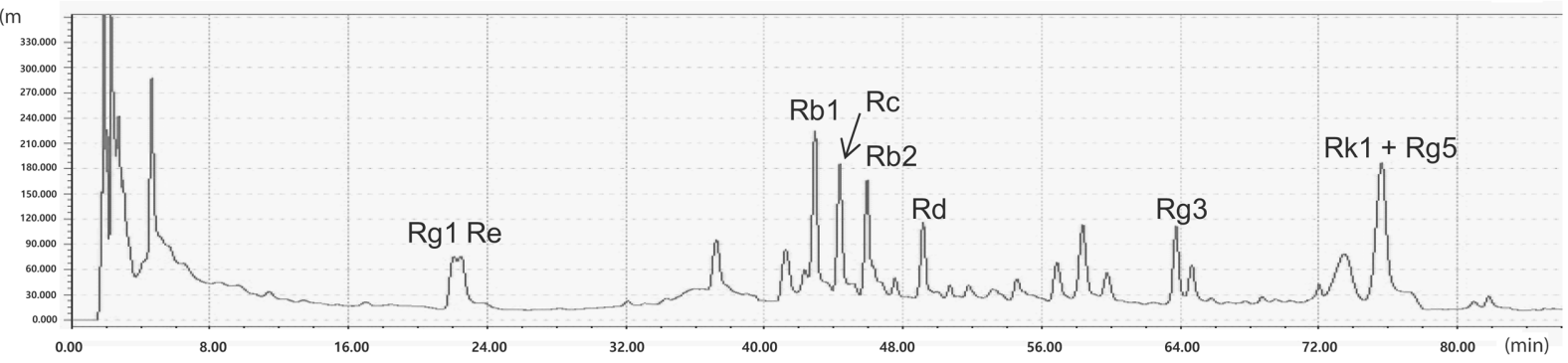

Fig. 1. HPLC chromatograms showing ginsenoside profiles of different ginseng varieties prepared under different conditions: $\mathrm{A}$, non-thermally extracted raw ginseng; B, thermally extracted raw ginseng; $\mathrm{C}$, white ginseng; $\mathrm{D}$, red ginseng; $\mathrm{E}$, black ginseng; $\mathrm{F}$, puffed white ginseng; $\mathrm{G}$, puffed red ginseng; $\mathrm{H}$, puffed black ginseng.

samples including thermally extracted raw, white, red, and black ginseng. The extraction yields of steamed raw, white, red and black ginseng were 36.22, 35.37, 40.47, and $33.80 \mathrm{~g}$ solid extract/100 g sample, respectively, and their crude saponin content was 33.95, 35.55, 37.55, and $34.15 \mathrm{mg} / \mathrm{g}$ dried ginseng, respectively. The extraction yields and crude saponin content of raw, white, red, and black ginseng were either significantly or not significantly different $(p<0.05)$, 


\section{$\mathbf{F}$}

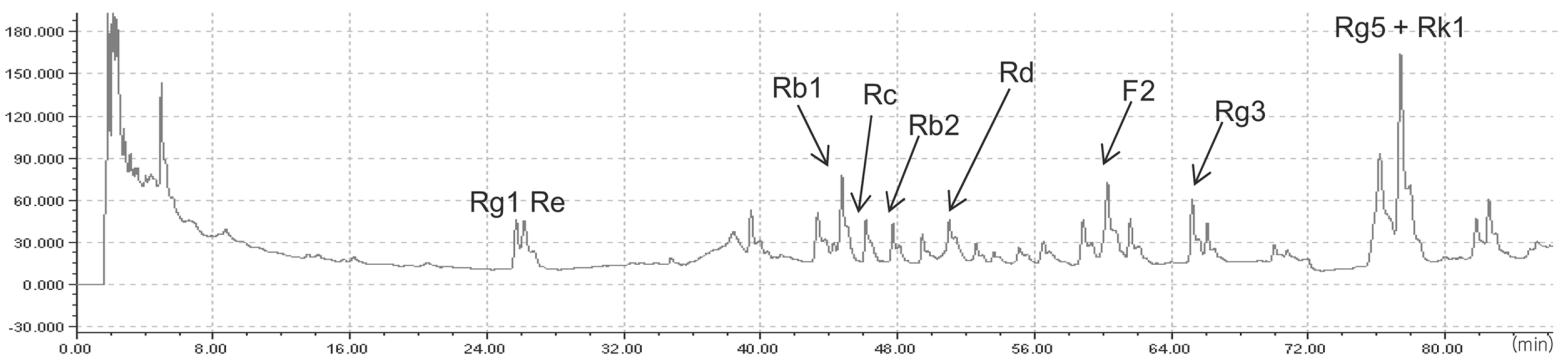

G

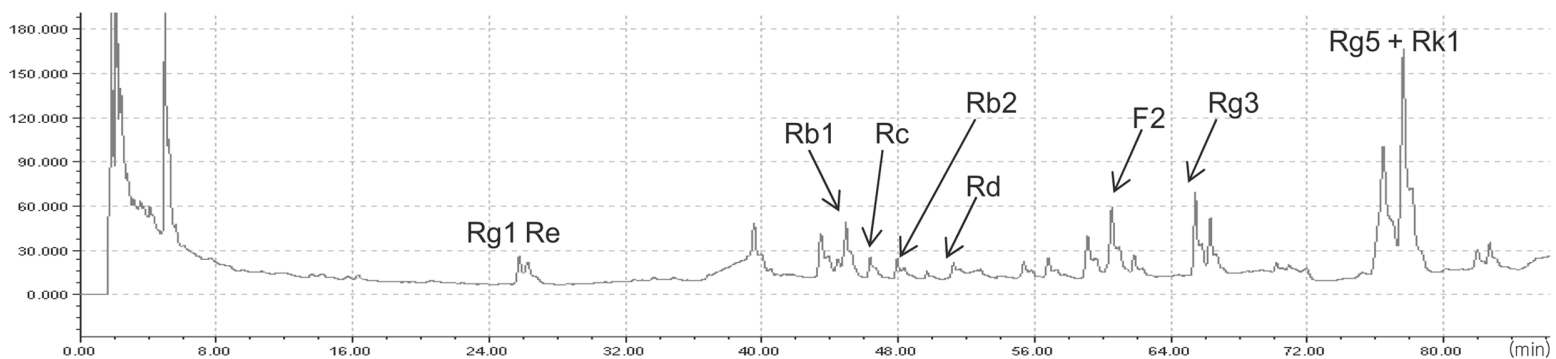

H

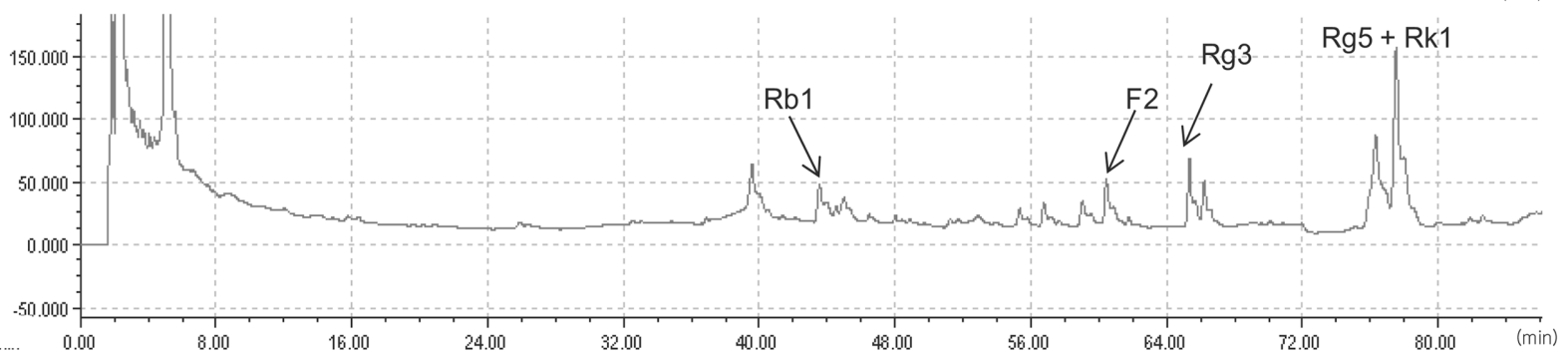

Fig. 1. Continued.

indicating that the steaming process did not cause much discrepancy in extraction yield or crude saponin content.

Figs. 1B, 1C, 1D, and 1E show the ginsenoside profiles of thermally extracted raw, white, red, and black ginseng. Table 2 shows their ginsenoside content. Thermally extracted raw and white ginseng showed similar ginsenoside profiles (Figs. 1B and 1C), while red and black ginseng were found to have different ginsenoside profiles (Figs. 1D and 1E). Red ginseng showed significant decreases in major ginsenosides, such as Rb1, Rb2, and Rc, while a minor ginsenoside, Rg3, was detected, compared with thermally extracted raw and white ginseng (Table 2, Fig. 1D). Moreover, black ginseng had significantly lower amounts of major ginsenosides ( $\mathrm{Rb} 1, \mathrm{Rb} 2, \mathrm{Rc}$, and $\mathrm{Rg} 1$ ) but higher amounts of minor ginsenosides ( $R g 3$, Rk1, and Rg5) compared with thermally extracted raw, white, and red ginseng (Table 2, Fig. 1E). These results suggested that the steaming process contributed to the conversion of major ginsenosides to minor ginsenosides, and the repeated steaming process (black ginseng) greatly enhanced the conversion of ginsenosides. This is consistent with previous reports on the occurrence of new types of ginsenosides including Rk1,
Rg5, and Rg3 under conditions of high temperature [15, 29, 30].

Compared with thermally processed raw ginseng, the total amount of the three major ginsenosides $\mathrm{Rb} 1, \mathrm{Rb} 2$, and Rc of black ginseng was reduced by $189.58 \mathrm{mg} / \mathrm{g}$ of saponin (Table 2). Conversely, ginsenoside Rg3, a degraded product of ginsenosides $\mathrm{Rb} 1, \mathrm{Rb} 2$, and $\mathrm{Rc}$ and undetected in thermally processed raw ginseng, increased by approximately six times, from 8.81 (red ginseng) to $53.61 \mathrm{mg} / \mathrm{g}$ saponin (black ginseng). Furthermore, other minor ginsenosides, Rk1 and Rg5, were newly produced from ginsenoside Rg3 in black ginseng (142.19 mg/g of saponin) (Table 2). The total content of these newly produced minor ginsenosides (Rg3, Rk1, and Rg5) in black ginseng was $195.80 \mathrm{mg} / \mathrm{g}$ saponin, nearly equal to the reduced amount of the three major ginsenosides (189.59 mg/g saponin). Ginsenoside Rg3 is most likely formed by eliminating the glycosyl residue at C-20 of protopanaxadiol-type saponins. Ginsenosides Rk1 and Rg5 are positional isomers to each other, depending on the position of a double bond between carbon-20 and -21 or between carbon-20 and -22, respectively. This double bond is known to be produced through the elimination of $\mathrm{H}_{2} \mathrm{O}$ at 
Table 2. Quantification of ginsenosides of raw and processed ginseng by drying, steaming, and puffing.

\begin{tabular}{|c|c|c|c|c|c|c|c|c|c|c|}
\hline & \multicolumn{10}{|c|}{ Ginsenoside (mg/g of saponin) $)^{1}$} \\
\hline & $\mathrm{Rb} 1$ & $\mathrm{Rb} 2$ & Rc & $\mathrm{Rd}$ & $\operatorname{Re}$ & $\operatorname{Rg} 1$ & F2 & $\operatorname{Rg} 3$ & Rk1+Rg5 & Total \\
\hline $\begin{array}{l}\text { Raw } \\
\text { ginseng } \\
\text { (non- } \\
\text { thermal) }\end{array}$ & $139.92 \pm 4.67^{c}$ & $50.44 \pm 0.83^{\mathrm{d}}$ & $142.17 \pm 11.10^{\mathrm{bc}}$ & $26.21 \pm 2.53^{c}$ & $65.75 \pm 21.83^{a}$ & $48.05 \pm 9.09^{\mathrm{ab}}$ & $\mathrm{ND}^{2)}$ & ND & ND & $472.54 \pm 45.09^{\mathrm{abc}}$ \\
\hline $\begin{array}{l}\text { Raw } \\
\text { ginseng } \\
\text { (thermal) }\end{array}$ & $198.48 \pm 4.29^{\mathrm{a}}$ & $115.00 \pm 10.47^{\mathrm{a}}$ & $197.66 \pm 8.46^{\mathrm{a}}$ & $53.42 \pm 1.72^{\mathrm{b}}$ & $39.27 \pm 7.70^{\mathrm{b}}$ & $31.54 \pm 9.84^{c}$ & ND & ND & ND & $635.37 \pm 40.62^{\mathrm{a}}$ \\
\hline $\begin{array}{l}\text { White } \\
\text { ginseng }\end{array}$ & $207.23 \pm 14.79^{a}$ & $124.68 \pm 2.30^{\mathrm{a}}$ & $207.26 \pm 13.28^{a}$ & $68.25 \pm 1.63^{\mathrm{a}}$ & $49.88 \pm 3.25^{\mathrm{ab}}$ & $33.55 \pm 2.33^{\mathrm{bc}}$ & ND & ND & ND & $660.88 \pm 36.70^{a}$ \\
\hline $\begin{array}{l}\text { Red } \\
\text { ginseng }\end{array}$ & $167.59 \pm 1.27^{b}$ & $96.56 \pm 1.06^{b}$ & $161.42 \pm 6.70^{b}$ & $59.23 \pm 6.69^{\mathrm{ab}}$ & $34.34 \pm 10.94^{\mathrm{bc}}$ & $33.88 \pm 5.48^{\mathrm{bc}}$ & ND & $8.81 \pm 1.80^{b}$ & ND & $561.83 \pm 31.55^{\mathrm{ab}}$ \\
\hline $\begin{array}{l}\text { Black } \\
\text { ginseng }\end{array}$ & $119.65 \pm 19.68^{c}$ & $80.11 \pm 8.27^{c}$ & $121.80 \pm 28.71^{c}$ & $59.24 \pm 11.88^{\mathrm{ab}}$ & $12.93 \pm 6.63^{\mathrm{cd}}$ & $14.59 \pm 2.19^{d}$ & ND & $53.61 \pm 6.07^{\mathrm{a}}$ & $142.19 \pm 36.9^{\mathrm{a}}$ & $604.12 \pm 105.67^{\mathrm{ab}}$ \\
\hline $\begin{array}{l}\text { Puffed } \\
\text { white } \\
\text { ginseng }\end{array}$ & $19.96 \pm 2.91^{\mathrm{d}}$ & $9.67 \pm 1.07^{e}$ & $10.99 \pm 1.03^{\mathrm{d}}$ & $10.32 \pm 5.31^{\mathrm{d}}$ & $5.25 \pm 3.01^{\mathrm{d}}$ & $55.09 \pm 17.06^{\mathrm{a}}$ & $15.65 \pm 2.70^{a}$ & $54.81 \pm 1.85^{\mathrm{a}}$ & $171.83 \pm 0.95^{\mathrm{a}}$ & $349.57 \pm 71.09^{b c}$ \\
\hline $\begin{array}{l}\text { Puffed } \\
\text { red } \\
\text { ginseng }\end{array}$ & $11.78 \pm 1.16^{\mathrm{d}}$ & $5.90 \pm 1.27^{e}$ & $5.51 \pm 1.46^{\mathrm{d}}$ & $2.45 \pm 0.27^{\mathrm{d}}$ & $3.14 \pm 0.13^{\mathrm{d}}$ & $2.33 \pm 0.29^{d}$ & $11.79 \pm 0.85^{\mathrm{a}}$ & $49.55 \pm 5.69^{a}$ & $184.91 \pm 22.78^{a}$ & $276.36 \pm 30.68^{c}$ \\
\hline $\begin{array}{l}\text { Puffed } \\
\text { black } \\
\text { ginseng }\end{array}$ & $9.84 \pm 1.14^{\mathrm{d}}$ & $0.68 \pm 0.01^{\mathrm{e}}$ & $1.07 \pm 0.37^{\mathrm{d}}$ & $0.72 \pm 0.01^{\mathrm{d}}$ & $3.30 \pm 0.11^{\mathrm{d}}$ & $2.33 \pm 0.13^{\mathrm{d}}$ & $8.53 \pm 2.01^{\mathrm{a}}$ & $54.62 \pm 1.48^{\mathrm{a}}$ & $161.24 \pm 4.95^{\mathrm{a}}$ & $247.33 \pm 9.87^{c}$ \\
\hline
\end{tabular}

${ }^{1)}$ Means with the same superscript letter in the same column are not significantly different by Duncan's multiple range test $(p<0.05)$.

${ }^{2)} \mathrm{ND}$ : not detected

carbon-20 of Rg3 by high pressure and temperature [30]. Therefore, these results suggest that minor ginsenosides $\mathrm{Rg} 3, \mathrm{Rk} 1$, and $\mathrm{Rg} 5$ are products of the degradation of major ginsenosides $\mathrm{Rb} 1, \mathrm{Rb} 2$, and Rc during steaming.

\section{Effect of Puffing Process}

The extraction yields and crude saponin content of puffed or non-puffed white, red, and black ginseng are compared in Table 1. The extraction yields of non-puffed white, red, and black ginseng were $35.37,40.47$, and $33.80 \mathrm{~g}$ solid extract/100 $\mathrm{g}$ of sample, respectively. The extraction yields of puffed white, red, and black ginseng were 50.80, 49.87 , and $58.60 \mathrm{~g}$ solid extract/100 g of sample, respectively; puffed white, red, and black ginseng showed significantly higher extraction yields compared with non-puffed white, red, and black ginseng. This result is consistent with previous reports [21, 23], which showed that the extraction yield and crude saponin content of puffed raw and red ginseng were higher than those of non-puffed raw and red ginseng. The ginseng puffing process induced an overall increase in extraction yield due to a modified outer layer structure with higher matrix porosity [31]. In addition, puffed white, red, and black ginseng had significantly higher crude saponin content (59.40-63.87 mg/g of saponin) than non-puffed white, red, and black ginseng (34.15$37.55 \mathrm{mg} / \mathrm{g}$ of saponin). It was reported that several polar ginseng saponins were transformed into lower molecular weight non-polar saponins during ginseng roasting [24]. As reported by Yoon et al. [32], an increase in crude saponin content after puffing was associated with a reduction in the molecular weight of saponin due to heat treatment and with the facilitation of saponin solubilization caused by the disruption of cell walls.

Figs. $1 F, 1 G$, and $1 \mathrm{H}$ show the ginsenoside profiles of puffed white, red, and black ginseng, respectively. The ginsenoside content of the three puffed ginseng varieties are presented in Table 2. Even though the puffing process greatly changed the ginsenoside profiles of white, red, and black ginseng (Figs. 1C vs. 1F, 1D vs. 1G, and $1 \mathrm{E}$ vs. $1 \mathrm{H}$ ), all the puffed types of ginseng were found to have similar ginsenoside profiles, very small amounts of the major ginsenosides ( $\mathrm{Rb} 1, \mathrm{Rb} 2, \mathrm{Rc}, \mathrm{Rd}, \mathrm{Re}$, and $\mathrm{Rg} 1$ ), and a nearmaximum amount of minor ginsenosides (F2, Rg3, Rg5, Rk1). A previous study [27] reported that 19 ginsenosides 
detected in black ginseng included minor ones such as $\mathrm{Rg} 3$, Rg5, and Rk1, but not F2. However, a minor ginsenoside, F2, was detected after white, red, and black ginseng were subjected to the puffing process (Table 2), suggesting that puffing is an effective method for producing ginsenoside F2. Moreover, drying of ginseng (white ginseng), steaming of ginseng (red ginseng), and repeated steaming (black ginseng) generated different ginsenoside profiles, while puffing of differently processed ginseng with different ginsenoside profiles resulted in similar ginsenoside profiles, indicating that the puffing process caused maximum conversion of major ginsenosides into minor ones known to exhibit a variety of biological activities, regardless of how the ginseng was processed.

More of the major ginsenosides ( $\mathrm{Rb} 1, \mathrm{Rb} 2, \mathrm{Rc}, \mathrm{Rd}$, and $\mathrm{Re}$ ) of puffed white ginseng were destroyed (84.8-94.6\%), compared with non-puffed white ginseng. In contrast, minor ginsenosides such as Rk1 and Rg5 increased by $13.4 \%$ in puffed black ginseng compared to non-puffed black ginseng. Moreover, the minor ginsenosides including F2, $\mathrm{Rk} 1$, and Rg5 were detected only after puffing white and red ginseng (Table 2, Fig. 1). The content of ginsenoside Rg3 in puffed white ginseng was similar to that of nonpuffed black ginseng. There was no significant difference in the amounts of minor ginsenosides such as F2, Rg3, Rk1, and Rg5 among the puffed white, red, and black ginseng; therefore, it was found that almost equal amounts of individual minor ginsenosides (F2, Rg3, Rk1, and Rg5) could be obtained by puffing white ginseng with much less energy and time compared to puffed red ginseng. Therefore, puffing white ginseng seems to be a more economical process to obtain the minor ginsenosides compared to the black ginseng process, which requires much more energy and time.

In this study, the effects of extraction temperature, steaming, and puffing on changes in the ginsenoside profiles of differently processed Korean ginseng roots were investigated. Thermal extraction was more efficient than non-thermal extraction, probably due to the conversion of some of the malonyl-ginsenosides to their corresponding neutral ginsenosides during thermal extraction. The steaming process did not have a great effect on either the extraction yield or the crude saponin content in any sample. The amounts of the major ginsenosides $R b 1, R b 2$, $\mathrm{Rc}, \mathrm{Rd}, \mathrm{Re}$, and Rg1 decreased, while the minor ginsenosides $\mathrm{Rg} 3, \mathrm{Rk1}$, and Rg5 appeared in red and black ginseng after steaming at high temperature. However, the steaming process takes a longer time: 4 days for red ginseng and 36 days for black ginseng. The puffing process produced a higher extraction yield and crude saponin content compared to non-puffed ginseng. As shown in the HPLC chromatograms (Fig. 1), the minor ginsenosides F2, Rg3, Rk1, and Rg5 were newly produced or increased significantly due to the puffing process. Therefore, the four minor ginsenosides, showing higher functionality and bioavailability, may be easily and feasibly obtained using the puffing process. To our knowledge, this is the first report that analyzes the quantitative and qualitative changes in a variety of ginsenosides in raw and processed ginseng from harvest to final product via drying, steaming, and puffing. Consequently, these results suggest that ginseng puffing has the great advantage of high minor ginsenoside transformation efficiency, with a much shorter processing time at a lower energy cost.

\section{Acknowledgments}

This research was supported by Korea Institute of Planning and Evaluation for Technology in Food, Agriculture, Forestry and Fisheries (IPET) through the High Valueadded Food Technology Development Program, funded by the Ministry of Agriculture, Food and Rural Affairs (MAFRA), Republic of Korea (116021-3).

\section{Conflict of Interest}

The authors have no financial conflicts of interest to declare.

\section{References}

1. Park JS, Park EM, Kim DH, Jung K, Jung JS, Lee EJ, et al. 2009. Anti-inflammatory mechanism of ginseng saponins in activated microglia. J. Neuroimmunol. 209: 40-49.

2. Cho WCS, Chung W-S, Lee SKW, Leung AWN, Cheng CHK, Yue KKM. 2006. Ginsenoside Re of Panax ginseng possesses significant antioxidant and antihyperlipidemic efficacies in streptozotocin-induced diabetic rats. Eur. J. Pharmacol. 550: 173-179.

3. Xie J-T, Mehendale SR, Li X, Quigg R, Wang X, Wang C-Z, et al. 2005. Anti-diabetic effect of ginsenoside Re in $o b / o b$ mice. Biochim. Biophys. Acta 1740: 319-325.

4. Park E-K, Choo M-K, Han MJ, Kim DH. 2004. Ginsenoside Rh1 possesses antiallergic and anti-inflammatory activities. Int. Arch. Allergy Immunol. 133: 113-120.

5. Shin JY, Lee JM, Shin HS, Park SY, Yang JE, Cho SK, et al. 2012. Anti-cancer effect of ginsenoside $F_{2}$ against glioblastoma multiforme in xenograft model in SD rats. J. Ginseng Res. 36: 86-92. 
6. Qu C, Bai Y, Jin X, Wang Y, Zhang K, You J, et al. 2009. Study on ginsenosides in different parts and ages of Panax quinquefolius L. Food Chem. 115: 340-346.

7. Yu H, Liu Q, Zhang C, Lu M, Fu Y, Im W-T, et al. 2009. A new ginsenosidase from Aspergillus strain hydrolyzing 20-Omulti-glycoside of PPD ginsenoside. Process Biochem. 44: 772-775.

8. Cheng L-Q, Na JR, Bang MH, Kim MK, Yang D-C. 2008. Conversion of major ginsenoside $\mathrm{Rb} 1$ to 20(S)-ginsenoside Rg3 by Microbacterium sp. GS514. Phytochemistry 69: 218-224.

9. Shinkai K, Akedo H, Mukai M, Imamura F, Isoai A, Kobayashi M, et al. 1996. Inhibition of in vitro tumor cell invasion by ginsenoside Rg3. Jpn. J. Cancer Res. 87: 357-362.

10. Lee H-U, Bae E-A, Han MJ, Kim D-H. 2005. Hepatoprotective effect of 20 (S)-ginsenosides Rg3 and its metabolite 20 (S)ginsenoside $\mathrm{Rh} 2$ on tert-butyl hydroperoxide-induced liver injury. Biol. Pharm. Bull. 28: 1992-1994.

11. Wei X, Chen J, Su F, Su X, Hu T, Hu S. 2012. Stereospecificity of ginsenoside $\mathrm{Rg} 3$ in promotion of the immune response to ovalbumin in mice. Int. Immunol. 24: 465-471.

12. Tian J, Zhang S, Li G, Liu Z, Xu B. 2009. 20(S)-ginsenoside Rg3, a neuroprotective agent, inhibits mitochondrial permeability transition pores in rat brain. Phytother. Res. 23: 486-491.

13. Lee $Y$, Jin $Y$, Lim W, Ji S, Choi S, Jang S, et al. 2003. A ginsenoside-Rh1, a component of ginseng saponin, activates estrogen receptor in human breast carcinoma MCF-7 cells. J. Steroid Biochem. Mol. Biol. 84: 463-468.

14. Quan L-H, Liang Z, Kim H-B, Kim S-H, Kim S-Y, Noh Y-D, et al. 2008. Conversion of ginsenoside $\mathrm{Rd}$ to compound $\mathrm{K}$ by crude enzymes extracted from Lactobacillus brevis LH8. J. Ginseng Res. 32: 226-231.

15. Sun BS, Gu LJ, Fang ZM, Wang CY, Wang Z, Lee MR, et al. 2009. Simultaneous quantification of 19 ginsenosides in black ginseng developed from Panax ginseng by HPLC-ELSD. J. Pharm. Biomed. Anal. 50: 15-22.

16. Kang KS, Yamabe N, Kim HY, Park JH, Yokozawa T. 2008. Therapeutic potential of 20(S)-ginsenoside Rg3 against streptozotocin-induced diabetic renal damage in rats. Eur. J. Pharmacol. 591: 266-272.

17. Chen J, Peng H, Ou-Yang X, He X. 2008. Research on the antitumor effect of ginsenoside Rg3 in B16 melanoma cells. Melanoma Res. 18: 322-329.

18. Yayeh T, Jung K-H, Jeong H-Y, Park J-H, Song Y-B, Kwak $\mathrm{Y}-\mathrm{S}$, et al. 2012. Korean red ginseng saponin fraction downregulates proinflammatory mediators in LPS stimulated RAW264.7 cells and protects mice against endotoxic shock.
J. Ginseng Res. 36: 263-269.

19. Kim JH, Pan JH, Cho HT, Kim YJ. 2016. Black ginseng extract counteracts streptozotocin-induced diabetes in mice. PLoS One 11: e0146843.

20. Payne FA, Taraba JL, Saputra D. 1989. A review of puffing processes for expansion of biological products. J. Food Eng. 10: 183-197.

21. An Y-E, Ahn S-C, Yang D-C, Park S-J, Kim B-Y, Baik M-Y. 2011. Chemical conversion of ginsenosides in puffed red ginseng. LWT-Food Sci. Technol. 44: 370-374.

22. Shim KS, Rhee SK. 2000. Effects of puffing treatments on the sensory qualities improving of ginseng extract J. Korean Prof. Eng. Assoc. 33: 106-115.

23. Kim J-H, Ahn S-C, Choi S-W, Hur N-Y, Kim B-Y, Baik M-Y. 2008. Changes in effective components of ginseng by puffing. J. Korean Soc. Appl. Biol. Chem. 51: 188-193.

24. Ha D-C, Ryu G-H. 2005. Chemical components of red, white, and extruded root ginseng. J. Korean Soc. Food Sci. Nutr. 34: 247-254.

25. Lee JH, Shen GN, Kim EK, Shin HJ, Myung CS, Oh HJ, et al. 2006. Preparation of black ginseng and its antitumor activity. Korean J. Orient. Physiol. Pathol. 20: 951-956.

26. Ando T, Tanaka O, Shibata S. 1971. Chemical studies on the oriental plant drugs $(\mathrm{XXV})$. Comparative studies on the saponins and sapogenins of ginseng and related crude drugs. Shoyakugaku Zasshi. 25: 28-32.

27. Sun B-S, Gu L-J, Fang Z-M, Wang C-Y, Wang Z, Lee M-R, et al. 2009. Simultaneous quantification of 19 ginsenosides in black ginseng developed from Panax ginseng by HPLCELSD. J. Pharm. Biomed. Anal. 50: 15-22.

28. Du XW, Wills RBH, Stuart DL. 2004. Changes in neutral and malonyl ginsenosides in American ginseng (Panax quinquefolium) during drying, storage and ethanolic extraction. Food Chem. 86: 155-159.

29. Kim WY, Kim JM, Han SB, Lee SK, Kim ND, Park MK, et al. 2000. Steaming of ginseng at high temperature enhances biological activity. J. Nat. Prod. 63: 1702-1704.

30. Kang KS, Kim HY, Yamabe N, Yokozawa T. 2006. Stereospecificity in hydroxyl radical scavenging activities of four ginsenosides produced by heat processing. Bioorg. Med. Chem. Lett. 16: 5028-5031.

31. Mariotti M, Alamprese C, Pagani MA, Lucisano M. 2006. Effect of puffing on ultrastructure and physical characteristics of cereal grains and flours. J. Cereal Sci. 43: 47-56.

32. Yoon S-R, Lee G-D, Kim H-K, Kwon J-H. 2010. Monitoring of chemical changes in explosively puffed ginseng and the optimization of puffing conditions. J. Ginseng Res. 34: 59-67. 